\title{
REGISTRATION AND SURFACE INSPECTION OF AUTOMOTIVE PRESSED PARTS BASED ON POINT CLOUD GENERATED BY OPTICAL MEASURING TECHNIQUES
}

\author{
Milan Blagojević ${ }^{1}$, Miroslav Živković, Marko Topalović
}

UDC: $338.246 .83+629.3 .01+528.7$

DOI: $10.24874 / m v m .2017 .43 .04 .01$

\begin{abstract}
Modern quality control has become unthinkable without optical measuring systems which are intensively used in automotive industry. This paper shows the analysis of preparation of models in terms of proper positioning in relation to the digitized model and the correct interpretation of the results of quality control. Experimental results verifying the method and the theory are shown. Part of tool for pressing and fabricated physical model of passenger car's suspension control arm is compared to CAD model. Presented results of measurements show that the optical measuring systems are powerful tool for quality control, analysis and discovering of causes of faults.
\end{abstract}

KEY WORDS: 3D digitizing, Triangulation, Registration, Inspection, CAD/CAM/CAE

\section{REGISTRACIJA I INSPEKCIJA POVRŠINA AUTOMOBILSKIH OTPRESAKA ZASNOVANA NA OBLAKU TAČAKA KOJI GENERIŠU OPTIČKI MERNI SISTEMI}

REZIME: Savremena kontrola kvaliteta je postala nezamisliva bez optičkih mernih uređaja koji se intenzivno koriste $\mathrm{u}$ automobilskoj industriji. $\mathrm{U}$ ovom radu prikazana je analiza pripreme modela $u$ pogledu pravilnog pozicioniranja $u$ odnosu na digitalizovani model $i$ tačna interpretacija rezultata kontrole kvaliteta. Eksperimentalni rezultati koji verifikuju metodu i teoriju su prikazani. Deo alata prese i njime izrađeno ocsilujuće rame su upoređeni sa CAD modelom. Prikazani rezultati merenja pokazuju da su optički merni sistemi moćan alat za kontrolu kvaliteta, analizu i otkrivanje uzroka grešaka.

KLJUČNE REČI: 3D digitalizacija, Triangulacija, Registracija, Kontrola, $\mathrm{CAD} / \mathrm{CAM} / \mathrm{CAE}$

${ }^{1}$ Received October 2016, Accepted October 2016, Available on line first December 2017 
Intentionally blank

Volume 43, Number 4, 2017 


\title{
REGISTRATION AND SURFACE INSPECTION OF AUTOMOTIVE PRESSED PARTS BASED ON POINT CLOUD GENERATED BY OPTICAL MEASURING TECHNIQUES
}

\author{
Milan Blagojević ${ }^{1}$, Miroslav Živković ${ }^{2}$, Marko Topalović ${ }^{3}$
}

\section{INTRODUCTION}

Classic measuring methods provide insufficient number of points for precise products surface reconstruction, because such free form surface can only be accurately reconstructed based on large number of measuring points. Non-contact digitizing is done through optical measuring systems, which captures hundreds of thousands of points in a single shot of the object. These measuring results provide very accurate computer reconstruction of shape, and so reduce development time and increase product quality. Reconstruction problems of this sort occur in diverse scientific and engineering application domains.

Optical measuring devices offer numerous advantages in comparison to the classic methods of quality control in automotive industry. Greatest advantage is possibility to determine deviation of entire geometry of measured object in reference to CAD geometry, in comparison to the classic coordinate measuring machines (CMM) which can perform control only in specific discrete points.

In the following sections, working principle of 3D scanner is described, and algorithms, on which this modern method is based, are discussed. Methodology presented in this paper is used for determination of deviation field for pressed part and scanned geometry of tool surface.

\section{3D SCANNER}

ATOS (Advanced Topometric Sensor) [1] is an industrial, high resolution, white light, optical 3D scanner (Figure 1). Instead of measuring single points, full part geometry is captured in a dense point cloud which can be translated into polygon mesh describing the object's surface and primitives precisely [2]. 3D scanner consists of sensor, control unit, computer hardware and software [3]. Sensor of optical measuring system consists of two high definition cameras and a projector.

The scanning is based on optical triangulation and stereo-viewing [4]. A projector is used to project striped fringe patterns onto the object's surface [5]. Change of shape of

\footnotetext{
${ }^{1}$ Milan Blagojević, Ph.D., student, University of Kragujevac, Faculty of engineering, Sestre Janjić 6, 34000 Kragujevac, Serbia, blagoje@kg.ac.rs

${ }^{2}$ Miroslav Živković, Ph.D., prof.., University of Kragujevac, Faculty of Engineering, Sestre Janjić 6, 34000 Kragujevac, Serbia, zile@kg.ac.rs

${ }^{3}$ Marko Topalović, Research assoc., University of Kragujevac, Faculty of engineering, Sestre Janjić 6, 34000 Kragujevac, Serbia, topalovic@kg.ac.rs
} 
lines projected on irregular surface of measured object is recorded with two cameras. These images are captured simultaneously by the two measurement cameras from different angles. ATOS digitizing sensor calculates its 3D coordinates based on visible reference objects - uncoded reference points (Fig. 1) [1]. This stereo-setup supports an easy and very accurate $3 \mathrm{D}$ capturing of the reference objects. Reference point diameter and strategy of point application to object's surface are function of used measuring volume. With the help of digital image processing, 3D-coordinates are computed fast and with high accuracy for up to 4 million camera pixels using the supplied high end System PCs. Coordinates of a point on measured object are obtained by triangulation using appropriate camera and projector points. The captured scan data is then automatically integrated in the predefined reference marker framework. The additional data captured with two cameras of the ATOS system are used to verify the calibration of the system, detect movements and high ambient light changes during the measurement and verify the matching accuracy of the individual scans into the global coordinate system.

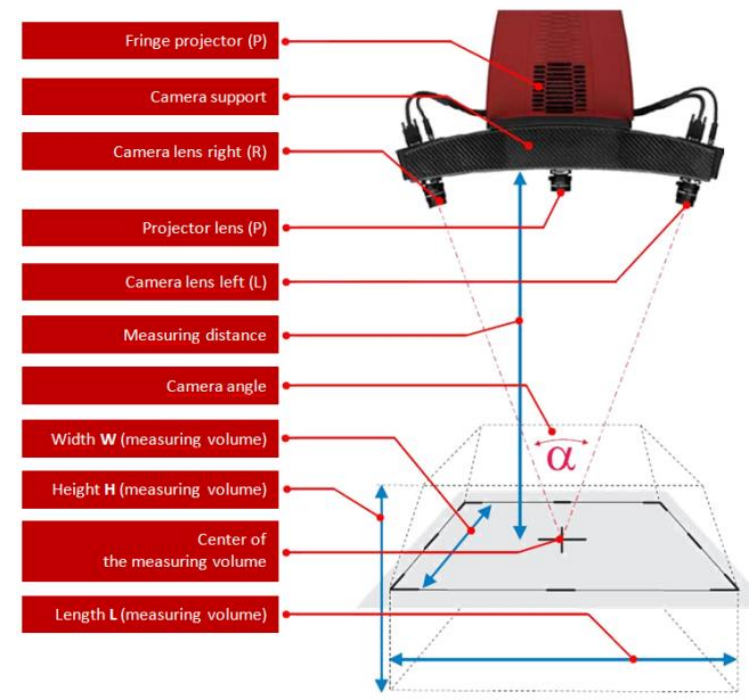

Figure 1. Measuring Volume of Optical Measuring System

Depending of complexity of measured object geometry, every 3D measurement consists of number of individual measurements. Each individual measurement means is scanning part of object surface which is visible with both cameras of measuring device [6]. Throughout multiple individual measurements, the entire surface of the measuring object is recorded while scanned surface is represented by the network of triangles (Figure 2). Polygons are oriented so that the normal is always directed towards the sensor. 

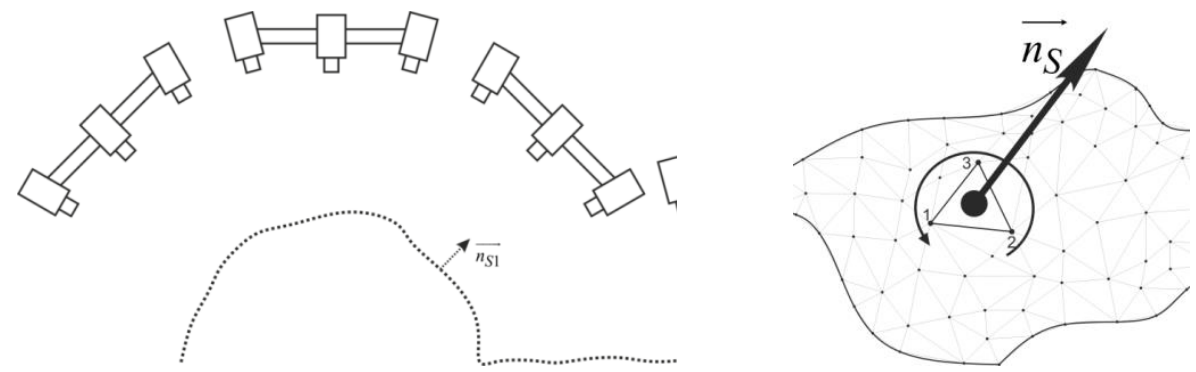

Figure 2. Normal vectors on digitized surface

\section{POINT CLOUD REGISTRATION}

The first of individual measurements is placed in arbitrary coordinate system, while every subsequent measurement overlaps with previous one, and it's placed in common coordinate system (coordinate system of the first measurement). This process is called registration and it is characteristic for all measuring systems, optical in particular, which operate on point clouds. Beside the task of individual measurement transformation into a global coordinate system, there is also a need to transform digitized model into the coordinate system of the CAD model. Most common methods for bringing two point clouds in mutually required position are ICP algorithm and barycentre method.

The majority of commercial optical measuring systems use modified ICP algorithm with matching points used for transformation already known. These points are uniquely determined by random application of adhesive reference objects on measured object surface and/or around it. Measuring devices automatically identify these matching points in every individual measurement. The fact that these reference objects are placed randomly in measured volume means that the reference objects identified in every individual measurement have unique configuration (mutual position). Searching through all relative position of all recorded points makes possible to determine corresponding matching point pairs required for registration. Latest generation optical measuring systems perform registration using all points in observed clouds and find matching points. These matching points are then used for bringing individual measurement into global coordinate system.

\subsection{Iterative Closest Point (ICP)}

ICP is an iterative algorithm for matching point clouds. Consider 2 point clouds where (point cloud A consists of $\mathrm{n}$ points) and (point cloud $\mathrm{B}$ consists of $\mathrm{m}$ points). We are interested in a one-to-one matching function that minimizes the root mean squared distance (RMSD) between A and B. Mathematically, we want to minimize the following:

$$
\operatorname{RMSD}(A, B, \mu)=\sqrt{\frac{1}{n} \sum_{a \in A}\|a-\mu(a)\|^{2}}
$$

Incorporating rotation and translation into the matching, we want to find: 


$$
\min _{\mu: A \rightarrow B, t \in R^{d}, R \in S O(d)} \sum_{a \in A}\|R a-t-\mu(a)\|^{2}
$$

where $\mathrm{R}$ is the rotation matrix, $\mathrm{t}$ is the translation vector and $\mathrm{SO}(\mathrm{d})$ is the set of special orthogonal matrices in $\mathrm{d}$ dimensions.

The ICP algorithm seeks to minimize the RMSD, by alternating between a matching step and a transformation step. In the matching step, given a certain rotation and translation, the optimal matching is calculated by minimizing the RMSD. In the transformation step, given a matching, the optimal rotation and translation are computed. This alternating process terminates when the matching remains unchanged in sucessive iterations. steps:

ICP algorithm, matching two point clouds, A and B, consists of the following

1. Initialize (identity matrix), $t=0$

2. Matching Step: Given and , compute optimal by finding $\min _{\mu} \operatorname{RMSD}(A, B, \mu)$

3. Transformation Step: Given $\mu$, compute optimal $R$ and $t$, by $\min _{R, t} R M S D(R A-t, B, \mu)$

4. Go to step 2 unless $\mu$ is unchanged.

The matching steps, find closest in the following manner: (a) construct Voronoi diagram on B and (b), do point-location in V or (B). In practice, a k-d tree is used to find the nearest-neighbour quickly. The matching step is usually the slowest part of the algorithm.

\section{SURFACE INSPECTION}

Poligonized mesh, obtained as a result of digitalization, with certain accuracy describes surface of measured object. Determination of measurement accuracy is beyond the scope of this paper. Normals on digitalized surface are oriented toward sensor of measuring system (Fig. 2).

During process called polygonization, software creates polygons (triangles) by connecting neighboring points in point cloud obtained by 3D scanning (Figure 2b). Software used for generation and analysis of deviation field imports CAD model and transform it in poligonized mesh, with adjustable polygonization parameters.

Deviation field is generated by software which loops through all points in poligonized mesh obtained by scanning, determines distance between the observed point and triangles in mesh obtained from CAD model (Figure 3). Searching for points is performed on search radius defined by user in direction normal to the current triangle. Since arbitrary point in poligonized mesh can belong to $\mathrm{n}$ triangles, this search is performed $\mathrm{n}$ times. When all searches are performed for observed point, obtained deviation is summarized as vectors. After search is performed for all points and for all triangles that they belong, entire deviation field is generated. Algorithm for deviation field generation is shown in Table 1. 


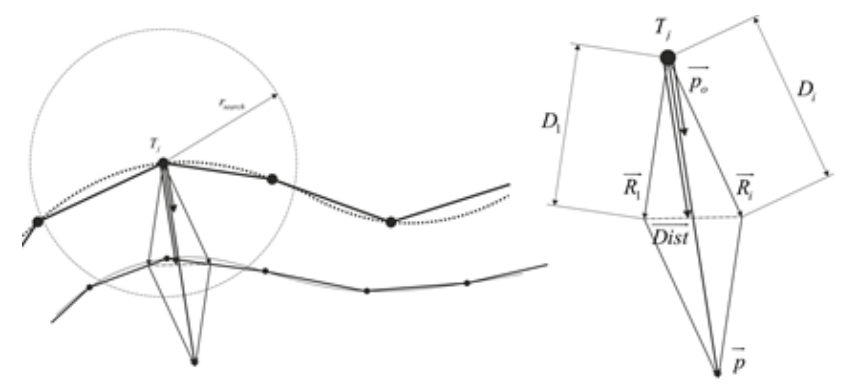

Figure 3. Determination of distance between observed point in scanned mesh and triangles in CAD mesh

Table 1. Algorithm for deviation field generation

\section{Loop over points in polygonized mesh of scanned model \\ Loop over triangles that observed points belong \\ Loop over triangles in polygonized mesh from CAD model}

Determination of intersection point defined by normal on triangle in polygonized mesh in current point through current triangle in $\mathrm{CAD}$ model polygonized mesh

\section{If intersection exists}

Calculate vector $(\mathrm{Ri})$

Based on coordinates of current point and intersection point calculate lenght (Di)

Based on coordinates of current point and intersection point

End of loop over triangles in polygonized mesh from CAD model

End of loop over triangles that these points belong

Determination of vector $(\mathrm{p})$ using vector summarization of $(\mathrm{Ri})$

Determination of unit vector ( $\mathrm{p} 0$ )

Determination of average distance (Dis) based on (Di)

End of loop over points in polygonized mesh of scanned model

Relationship between normals on polygonized mesh has influence on results interpretation for deviation field (Figure 4). In case when scalar product of normals for adjacent triangles is positive, (normals facing the same section of space), positive deviation means that on that spot there is more material then needed and vice versa. In case when mentioned scalar product is negative, previous analysis have oposite conclusions. In practice, it means that convex surfaces, for example pressed parts, have normal which exit material for CAD model and normal which face sensor for digitalized model. Scalar product of these normal is positive. On the other hand, scanned models of pressing tools have their normal facing cavity. 


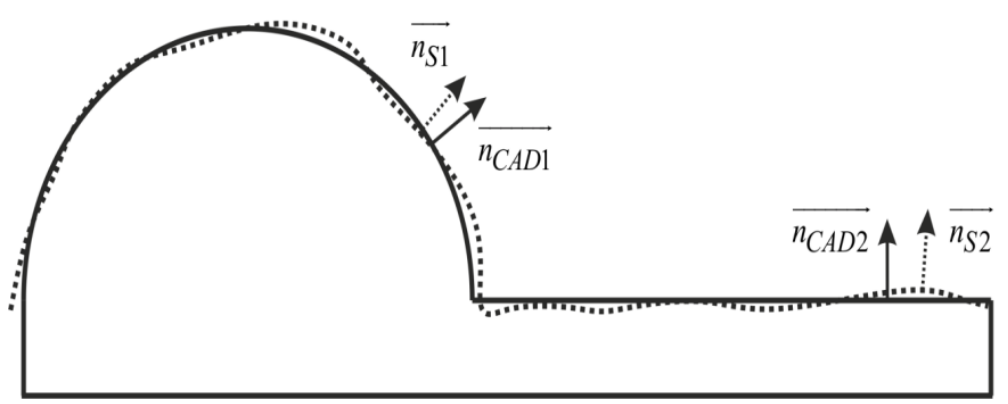

Figure 4. Normal on scanned surface and CAD model

\section{RESULTS}

The methods presented will be confirmed on the example of passenger car's suspension control arm. Based on the 3D digitalization of physical model using optical measuring systems TRITOP and ATOS (Figure 5) the reconstruction of CAD model (Figure 6 ) is performed [2]. Then, pressing tool design is carried out, fabrication and 3D digitizing of tool surface. Digitized surface of pressing tool and pressed part is shown in Figure 7.

All models are set so that the normal directed out of paper. When determining the deviation field of physical model in reference to CAD, models on Figures 6 and $7 \mathrm{~b}$ are compared. In this case the dot product of normal vectors is a positive. On other side, when determining the deviation field of pressing tool in reference to CAD, models on Figures 6 and $7 \mathrm{a}$ are compared and the dot product of normal vectors is a negative. As a result, deviation fields are generated. Based on these fields engineers can determine necessary steps to improve matching between shape of the real pressed part and the desired shape of the 3D CAD model. These steps could mean changing the shape of the pressing tool, additional treatment of pressed part or any other change in the production process. Deviation field for both cases of dot products of normal vectors are shown in Figures 8 and 9.

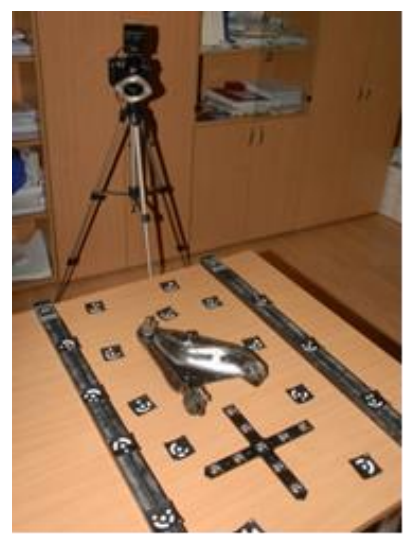

(a)

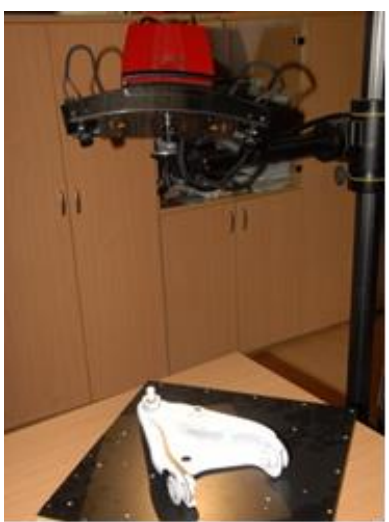

(b)

Figure 5. 3D digitization of physical model: (a) TRITOP and (b) ATOS 


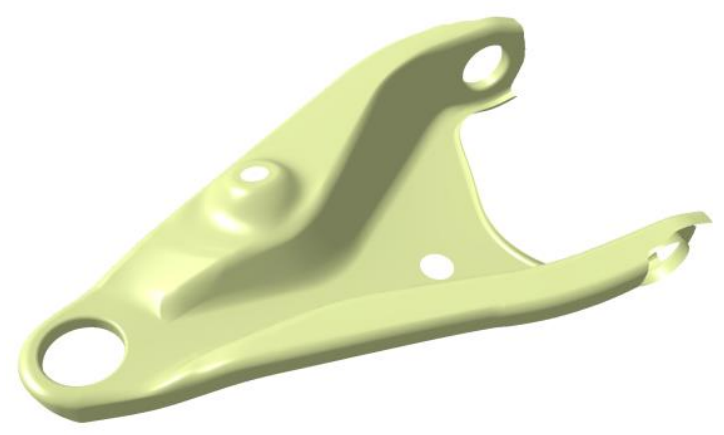

Figure 6. CAD model of passenger car's suspension control arm

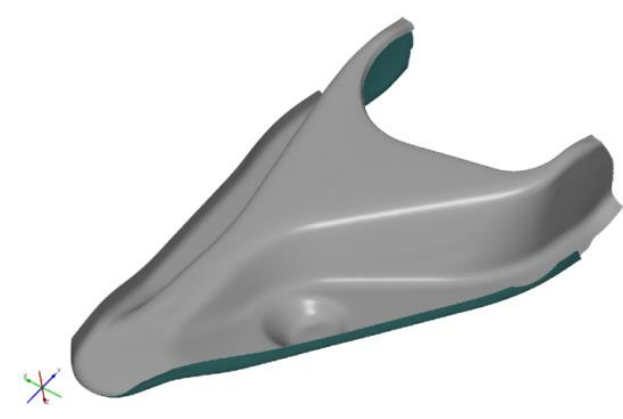

(a)

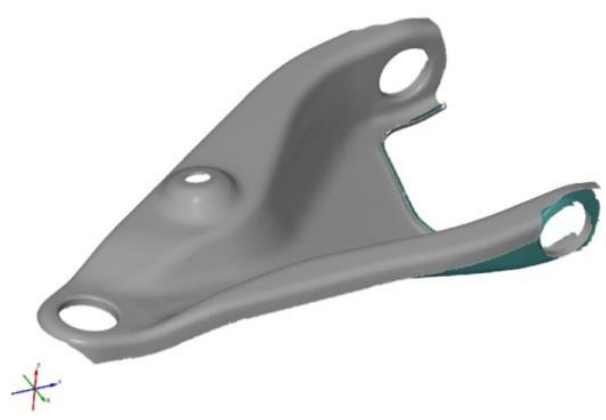

(b)

Figure 7. Digitized surface of (a) pressing tool and (b) pressed part
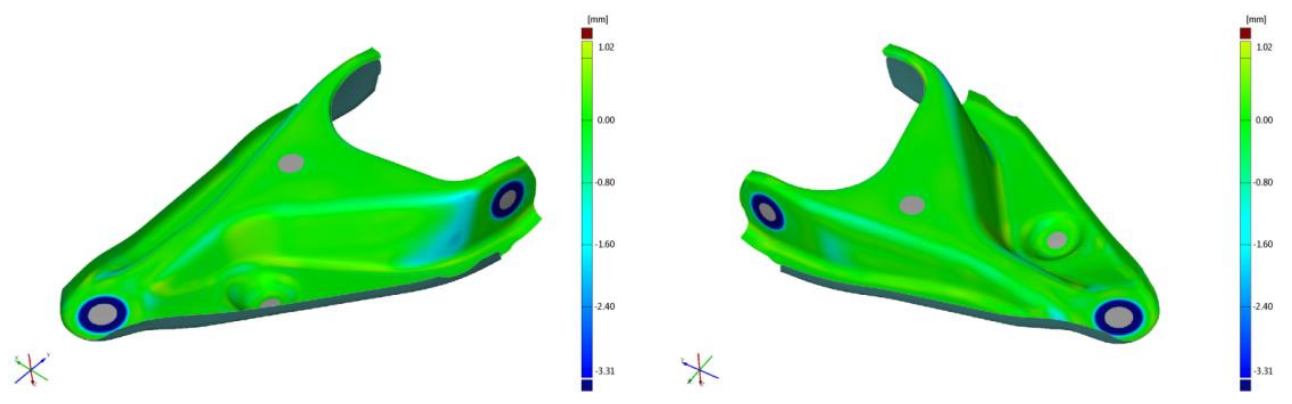

Figure 8. Deviation field in case when dot products is less than zero 


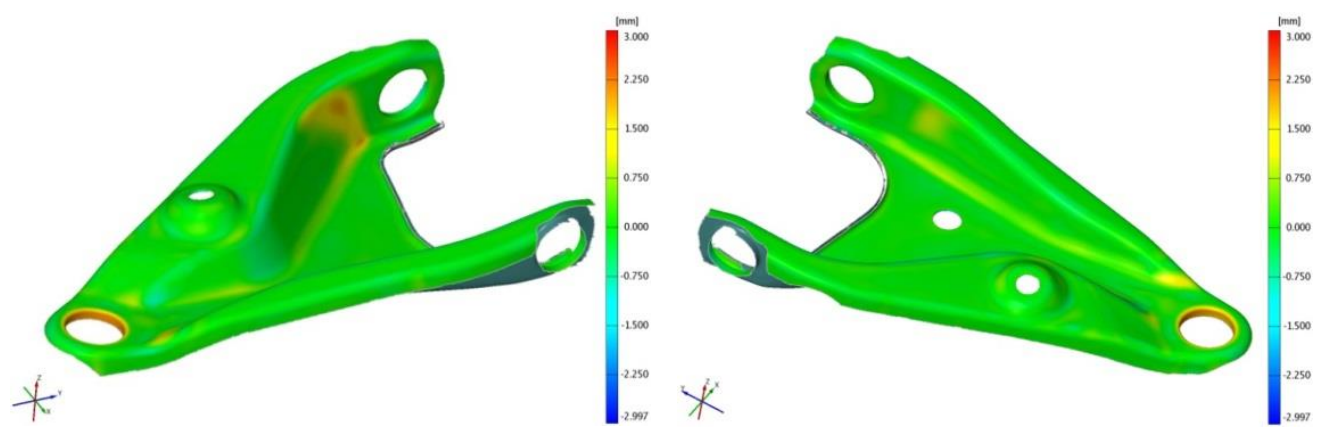

Figure 9. Deviation field in case when dot products is greater than zero

\section{CONCLUSION}

During recent years, optical measuring systems, 3D scanners in particular, become standard for quality control in automotive industry. Optical digitizing is part of advanced process chains in the development of products and production processes for sheet metals and tools. Presently optical measuring systems are used to optimize time, costs and quality of the product, thus increasing the competitiveness of companies. In the future, this measuring technology will be used increasingly for automated inspection tasks due to its further integration in production processes and the availability of powerful data processing systems.

In this paper theoretical basics on which devices for pressed part quality control operate are presented. Emphasis is placed on registration process and generation of deviation field, as most important components of quality control. Knowing theoretical basics enables proper understanding of obtained model and correct interpretation of measuring results.

The application examples showed the practical use of optical measuring technology in automotive industry. Thanks to the non-contact data acquisition, the influence on the measuring object is very low, so that a large number of measuring points does not negatively affect the tested object. Precise deviation field requires high density point clouds. This allows accurate measurement and capture of the shape and size of the visible surface of almost any 3D object. Their usability for pressed part deviation analysis gives them significant advantage in comparison to the CMM.

\section{ACKNOWLEDGMENT}

The part of this research is supported by Ministry of Education, Science and Tehnological Development, Republic of Serbia, Grant TR32036.

\section{REFERENCES}

[1] ATOS, User Manual - Software, atos_v61_1st_en_rev-a, 26-Feb-2008.

[2] Blagojević M., Živković M., Algorithm for 3D Surface Reconstruction based on Point Cloud generated by Optical Measuring Techniques, Mobility and Vehicle Mechanics, Vol. 37, No. 1, pp. 63-77, 2011. 
[3] Blagojević M., Application of optical measuring systems in modelling and simulation (in Serbian), Faculty of Mechanical Engineering in Kragujevac, University of Kragujevac, 2009.

[4] Li, Y. Gu P., Free-form surface inspection techniques state of the art review, Computer-Aided Design, Vol. 36, pp. 1395-1417, 2004.

[5] Li H., Liu S., Zhang H., 3D shape measurement of optical free-form surface based on fringe projection, Proc. SPIE 8082, 80822Z, http://dx.doi.org/10.1117/12.889361, 2011.

[6] Zou L., Samarawickrama D., Seymour K., Stout K., Free Form Surface Measurement Using Non-Contact Measuring Methodology, Proceedings, XVII IMEKO World Congress, June 22 - 27, Dubrovnik, Croatia, 2003. 